\title{
Potassium, Rubidium and Cesium Hydrides as Dehydrogenation Catalysts for the
}

\author{
Lithium Amide / Magnesium Hydride System \\ Tolulope Durojaiye ${ }^{\mathrm{a}}$, Jalaal Hayes ${ }^{\mathrm{b}}$ and Andrew Goudy ${ }^{\mathrm{c} *}$ \\ Department of Chemistry \\ Delaware State University \\ 1200 N. DuPont Highway, DE 19901. \\ otusko@yahoo.com, ${ }^{b}$ jalaal.hayes@gmail.com, and ${ }^{\mathrm{c}}$ agoudy@desu.edu \\ *Corresponding Author - Phone: 302-857-6534, Fax: 302-857-6539
}

\begin{abstract}
In this study, the effectiveness of several alkali metal hydrides $(\mathrm{KH}, \mathrm{RbH}$ and $\mathrm{CsH})$ for improving the hydrogen desorption properties of a $2 \mathrm{LiNH}_{2} / \mathrm{MgH}_{2}$ mixture was studied. Results showed that the relative effectiveness of these additives in decreasing the hydrogen desorption temperature, lowering the activation energy and increasing desorption rates from the mixtures is in the order: $\mathrm{RbH}>\mathrm{KH}>\mathrm{CsH}>$ Un-catalyzed. Modeling studies showed that diffusion through a $\mathrm{Li}_{2} \mathrm{Mg}(\mathrm{NH})_{2}$ product layer is the rate-controlling process. It is believed that the alkali elements: $\mathrm{K}, \mathrm{Rb}$ and $\mathrm{Cs}$ partially replace the $\mathrm{Li}$ in the product layer. This may have an inductive effect in which the $\mathrm{N}-\mathrm{H}$ bond is weakened thus leading to lower desorption enthalpies. The lattice expansion caused by substitution of the larger alkali elements for Li may also allow for faster diffusion and increased desorption rates.
\end{abstract}

Keywords: Hydrogen storage materials; lithium amide; desorption kinetics; potassium hydride; rubidium hydride; cesium hydride 


\section{Introduction}

Rising energy costs and the need to minimize over-dependence on fossil fuels have led to research studies on alternative energy sources. Hydrogen is now widely recognized as an important clean energy carrier. Efforts have been made to find solid state materials for hydrogen storage applications [1-3]. A suitable material should be able to absorb large amounts of hydrogen rapidly and reversible at moderate temperatures. Complex hydrides have been widely studied for hydrogen storage applications due to their light weight and high hydrogen-holding capacities [4-13]. One of the most promising materials was the lithium nitride/imide system. P. Chen et al [14] reported that this system had a hydrogen storage capacity of $11.5 \mathrm{wt}$ \% thus making it a prime candidate for practical applications. However, practical use of amides and imides has been limited by their poor absorption kinetics despite their high hydrogen capacity and moderate operating temperatures. Luo [15] reported the preparation of a new type of hydrogen storage system by partial substitution of $\mathrm{Li}$ by $\mathrm{Mg}$ in lithium amide $\left(2 \mathrm{LiNH}_{2} / \mathrm{MgH}_{2}\right)$. The new storage material can reversibly store hydrogen at 32 bars and $200{ }^{\circ} \mathrm{C}$. When $\mathrm{LiNH}_{2}$ and $\mathrm{MgH}_{2}$ are ball-milled together in ratio 2:1, the dehydrogenation product is a ternary imide $\mathrm{Li}_{2} \mathrm{Mg}(\mathrm{NH})_{2}$. Luo suggested that the dehydrided product can be formed using a two-step process which involves the formation of mixed imide phase. In this method, $\mathrm{LiNH}_{2}$ and $\mathrm{MgH}_{2}$ undergo initial conversion to $\mathrm{Mg}\left(\mathrm{NH}_{2}\right)_{2}$ and $\mathrm{LiH}$ when heated for $2 \mathrm{hrs}$ at $200{ }^{\circ} \mathrm{C}$ under $100 \mathrm{bar}$ of hydrogen. These products are reversibly decomposed to form $\operatorname{Li}_{2} \mathrm{Mg}(\mathrm{NH})_{2}$ with evolution of hydrogen. The reaction for this process is shown below.

$$
2 \mathrm{LiNH}_{2}+\mathrm{MgH}_{2} \rightarrow \mathrm{Mg}\left(\mathrm{NH}_{2}\right)_{2}+2 \mathrm{LiH} \leftrightarrow \mathrm{Li}_{2} \mathrm{Mg}(\mathrm{NH})_{2}+2 \mathrm{H}_{2}
$$


Recently, more work has been focused on lowering the desorption temperature and improving the kinetics of the $2 \mathrm{LiNH}_{2} / \mathrm{MgH}_{2}$ system with effective catalysts. Additives such as $\mathrm{V}, \mathrm{V}_{2} \mathrm{O}_{5}, \mathrm{VCl}_{3}$ [16], Graphite -supported $\mathrm{Ru}$ nanoparticles [17], $\mathrm{LiBH}_{4}$ and $\mathrm{ZrCo}_{3} \mathrm{H}[18,19]$, Single walled carbon nanotubes [20], $\mathrm{NaOH}$ [21], lithium halides [22,23] and $\mathrm{Si}$ and $\mathrm{Al}$ [24] have been tried. But alkali metal based hydrides have been found to be among the most effective catalytic additives [25-27]. Liu et al [25] found that the partial substitution of $\mathrm{Mg}$ or $\mathrm{Li}$ in the $\mathrm{Li}$ Mg-N-H system with $\mathrm{Na}$ decreased the hydrogen desorption temperature by $\sim 10{ }^{\circ} \mathrm{C}$. Li et al [26] found that the introduction of $\mathrm{RbF}$ into the $\mathrm{Mg}\left(\mathrm{NH}_{2}\right)_{2}-2 \mathrm{LiH}$ system significantly decreased its dehydrogenation temperature and enhanced its hydrogen storage kinetics. Wang et al [27] reported that doping the system with $\sim 3$ mol \% of $\mathrm{KH}$ vastly improved the desorption and absorption kinetics of $\left(\mathrm{Mg}\left(\mathrm{NH}_{2}\right)_{2}+2 \mathrm{LiH}\right)$. Other studies by Durojaiye et al [28], Luo et al 29] and Li et al [30] have verified this. But perhaps the most effective catalytic additive to date for the $2 \mathrm{LiNH}_{2} / \mathrm{MgH}_{2}$ system has been $\mathrm{RbH}$. Durojaiye et al [31] reported that $\mathrm{RbH}$ lowered the desorption temperature of this system by $90{ }^{\circ} \mathrm{C}$ and increased its reaction rate by 65 fold.

In this work an attempt has been made to compare the thermodynamics and kinetics of hydrogen release from the $2 \mathrm{LiNH}_{2} / \mathrm{MgH}_{2}$ system catalyzed by hydrides of Group 1 elements (KH, $\mathrm{RbH}$ and $\mathrm{CsH})$. Jacobs et al $[32,33]$ reported that all of these elements $(\mathrm{K}, \mathrm{Rb}$ and $\mathrm{Cs})$ form stable ternary amides with magnesium. Assuming that they can also be accommodated by the imide, they should all be effective catalytic additives for this system. Modeling studies have also been attempted to determine what controls the hydrogen desorption rates. The results should lead to better understanding of this system.

\section{Materials and methods}


The starting materials used for this research were obtained from Sigma Aldrich. The $\mathrm{MgH}_{2}$ was hydrogen storage grade (98\% pure) and the $\mathrm{LiNH}_{2}$ was $95 \%$ pure. The $\mathrm{KH}$ was obtained commercially whereas the $\mathrm{RbH}$ and $\mathrm{CsH}$ were synthesized in the laboratory. The $\mathrm{RbH}$ and $\mathrm{CsH}$ were prepared using a mechanical alloying method similar to the one described in a previous publication [31] and by Elansari et al [34]. In this method, a $45 \mathrm{ml}$ stainless steel vial was placed into an argon filled glove box and approximately 4-5 g of alkali metal was added to it along with ten stainless steel balls (10 $\mathrm{mm}$ in diameter). The vial was covered with a special lid that allowed it to be pressurized and depressurized. The vial was evacuated to remove the argon and approximately 90 psi of $99.999 \%$ pure hydrogen gas hydrogen was introduced. The vial was then placed into a Fritsch pulverisette 7 planetary mill and milled at an initial rotation rate of 100 rpm for $15 \mathrm{~min}$. The rotation rate was progressively increased by $25 \mathrm{rpm}$. The $15 \mathrm{~min}$ milling time was kept constant until $250 \mathrm{rpm}$ was reached. At $250 \mathrm{rpm}$ the sample was milled for a $12 \mathrm{~h}$ time period, which included 36 cycles of 20 min milling and 10 min pause times. It should be noted that before the start of each milling cycle the vial was re-pressurized with hydrogen to 90 psi. After the $12 \mathrm{~h}$ milling cycle was completed the vial was re-pressurized and placed in an oven at $120{ }^{\circ} \mathrm{C}$ for $1 \mathrm{~h}$. This resulted in the formation of a white powder. Catalyzed mixtures of 1.9 $\mathrm{LiNH}_{2} / 1.1 \mathrm{MgH}_{2}$ were also prepared by mechanical alloying. The $10 \%$ excess of $\mathrm{MgH}_{2}$ was used to suppress ammonia formation. The procedure consisted of placing some 1.9 $\mathrm{LiNH}_{2} / 1.1 \mathrm{MgH}_{2}$, along with $3.3 \mathrm{~mol} \%$ of catalyst in a $65 \mathrm{~mL}$ stainless steel milling pot along with two $12 \mathrm{~mm}$ and four $6 \mathrm{~mm}$ stainless steel balls. Each mixture was milled in a SPEX 8000D mixer/mill for $2 \mathrm{~h}$ under argon. X-ray characterizations of the mixtures were done in a Panalytical X'Pert Pro MPD X-Ray Diffractometer Model PW3040 Pro using copper K-alpha radiation. Samples were covered with a Kapton film to protect them from air and moisture. 
Pressure Composition Isotherm (PCI) and Temperature Programmed Desorption (TPD) analyses were done on each mixture using a Gas Reaction Controller-PCI unit that was manufactured by the Advanced Materials Corporation, Pittsburgh, PA. Isotherm measurements were done in a temperature range of $190-230{ }^{\circ} \mathrm{C}$. Data were collected and analyzed using a Lab View based software program. TPD measurements were carried out between $30-300{ }^{\circ} \mathrm{C}$. Differential Thermal Analyses (DTA) were carried out under an argon atmosphere using a Perkin Elmer TGA/DTA instrument. DTAs were carried out between $30-300{ }^{\circ} \mathrm{C}$ for the various mixtures at several scan rates. Data obtained from the DTA curves were used to calculate the activation energy from Kissinger plots.

Desorption kinetics measurements were carried out using a Sievert's apparatus. This was an all stainless steel system that contained valves and ports for adding hydrogen, venting and evacuating. The kinetics was monitored by measuring the rate of pressure change in remote reservoirs as gas was released from the sample chamber. A thermocouple was placed in the sample holder to monitor any changes in the temperature of the sample. Measurements were done in the two-phase plateau region at $210{ }^{\circ} \mathrm{C}$ at the same temperature and thermodynamic driving force. Similar thermodynamic driving forces were achieved for all of the experiments by using the same ratio of plateau pressure to applied pressure $\left(\mathrm{P}_{\mathrm{m}} / \mathrm{P}_{\mathrm{op}}\right)$ to each sample. Further details about this procedure have been described elsewhere [35-37].

\section{Results and discussion}

\subsection{X-ray Diffraction (XRD) Analysis}

Fig. 1 shows the X-ray diffraction patterns of the catalysts used. A comparison of the peaks in the three XRD profiles reveals some systematic trends. As expected, the peaks for 
corresponding Miller indices generally shift to smaller angles as the size of the alkali metal increases. The calculated lattice parameter "a", for $\mathrm{KH}, \mathrm{RbH}$ and $\mathrm{CsH}$ are 5.70 \pm 0.010 , $6.01 \pm 0.012$ and $6.37 \pm 0.015$, respectively. These values are in good agreement with those reported by Elansari et al [34]. Fig. 2 shows the XRD profiles of the "As Milled" samples with and without the catalysts. It can be seen that the $\mathrm{KH}, \mathrm{RbH}$ and $\mathrm{CsH}$ doped mixtures all follow the same pattern. No catalysts' peaks could be identified in these mixtures. A possible reason for the absence of catalyst peaks is that the alkali hydrides may be converted to other species such as amides during the milling process. However, this could not be confirmed from the peaks that are present in the diffraction patterns. This is because the major peaks for $\mathrm{KNH}_{2}, \mathrm{RbNH}_{2}$ and $\mathrm{CsNH}_{2}$ occur at angles that overlap with the magnesium amide peaks.

Fig. 3 shows the dehydrided XRD profiles of the mixtures. Hu and Fichtner [38] reported that the dehydrided mixtures of the $\mathrm{KH}$ doped and the un-catalyzed mixtures result in the formation of a new compound known to be $\mathrm{Li}_{2} \mathrm{Mg}(\mathrm{NH})_{2}$. The XRD patterns in Fig. 3 are in good agreement with those reported by Hu and Fichtner. They used in situ X-ray diffraction and neutron diffraction to show that $\mathrm{Li}_{2} \mathrm{Mg}(\mathrm{NH})_{2}$ has an orthorhombic structure at temperatures below $350{ }^{\circ} \mathrm{C}$ that undergoes a phase transition to primitive cubic at $350^{\circ} \mathrm{C}$ and to face centered cubic at $500{ }^{\circ} \mathrm{C}$. The $\mathrm{RbH}$ doped mixtures exhibits the same XRD pattern as the un-catalyzed and $\mathrm{KH}$ doped mixtures when dehydrided. However, the $\mathrm{CsH}$ doped sample showed a different XRD pattern than the others when dehydrided. The set of peaks at 18.3 and 20.2 degrees in the patterns for the other dehydrided mixtures could not be found in the dehydrided mixture of the $\mathrm{CsH}$ doped sample. This sample also possesses a strong singlet peak at 51.6 degrees whereas the others display multiple peaks in this same region. The fact that the CsH doped mixture did not produce the same diffraction pattern as the other mixtures is strong evidence that the 
Cs-containing product has a different crystal structure than the others. The XRD data indicate that the $\mathrm{KH}$ and $\mathrm{RbH}$ doped product is $\operatorname{Li}_{2} \mathrm{Mg}(\mathrm{NH})_{2}$ with a cubic structure. The CsH doped product has a tetragonal structure which does not appear to be $\operatorname{Li}_{2} \mathrm{Mg}(\mathrm{NH})_{2}$. The identity of this product is not known at this time. Fig 4 shows the XRD profiles of the rehydrided mixtures. An XRD pattern for $\mathrm{Mg}\left(\mathrm{NH}_{2}\right)_{2}$ has also been included for comparison. All of the rehydrided patterns show some evidence of the $\mathrm{Mg}\left(\mathrm{NH}_{2}\right)_{2}$. This confirms that the mixtures cycle between $\mathrm{Mg}\left(\mathrm{NH}_{2}\right)_{2}+2 \mathrm{LiH}$ and $\mathrm{Li}_{2} \mathrm{Mg}(\mathrm{NH})_{2}$, thus indicating reversibility.

It has been reported that the $\mathrm{KH}$ doped mixture $2 \mathrm{LiNH}_{2} / \mathrm{MgH}_{2}$ shows peaks belonging to the $\mathrm{KH}$ catalyst at 27.2 degrees in the dehydrided and rehydrided mixtures $[15,30]$. A peak at 27.1 degrees does appear in the diffraction patterns for the KH catalyzed mixtures in Figs. 3 and 4. This peak corresponds very closely to the (111) peak in the diffraction patterns for the KH dopant in Fig 1. Thus it is clear that the KH dopant is present throughout the process. However, this is not the case in the $\mathrm{RbH}$ and $\mathrm{CsH}$ catalyzed mixtures. Peaks at 25.8 and 23.3 degrees appear in the diffraction patterns for the $\mathrm{RbH}$ and $\mathrm{CsH}$ catalyzed mixtures in Fig. 4 but not in Fig. 3. The appearance of these peaks in Fig. 4 confirms that the catalysts have been regenerated. The fact that no $\mathrm{RbH}$ or $\mathrm{CsH}$ peaks appear in the dehydrogenated patterns in Fig. 3 indicate that the hydrides have decomposed into the metals, $\mathrm{Rb}$ and $\mathrm{Cs}$. This is most likely due to the fact that both of these hydrides decompose at $\sim 170{ }^{\circ} \mathrm{C}$, which is below the temperature of $210{ }^{\circ} \mathrm{C}$ used in these experiments. Since both of the resulting metals have very low melting points (39.5 and $28.4{ }^{\circ} \mathrm{C}$, respectively) they would be liquefied at the relatively high temperature of $210{ }^{\circ} \mathrm{C}$ used in these experiments. They form sticky amorphous pastes when cooled to room temperature and thus they would not be expected to produce peaks in the XRD patterns. We found this to be the case when attempting to obtain XRD patterns for the 
pure $\mathbf{R b}$ and Cs metals. No peaks resulted due to the lack of a crystalline structure in these materials. Another possible explanation for the absence of $\mathrm{Rb}$ and $\mathrm{Cs}$ peaks could be that these metals react to produce other species such as amides/imides. However, the absence of peaks in the XRD patterns corresponding to novel amides or amide/imides indicate that this is not the case. Thus the most likely explanation for the lack of Rb or Cs peaks is that they are amorphous under the conditions used. The high pressure of 100 bars during rehydriding is enough to regenerate the metal hydrides. It should be noted that KH doesn't decompose until $400{ }^{\circ} \mathrm{C}$. Thus it remains intact throughout the experiments.

\subsection{Temperature Programmed Desorption (TPD) Analysis}

Fig. 5 shows the Temperature Programmed Desorption (TPD) analyses of the various mixtures of $1.9 \mathrm{LiNH}_{2}+1.1 \mathrm{MgH}_{2}$ with and without the catalysts. The samples were heated from 30 to $300{ }^{\circ} \mathrm{C}$ at $4{ }^{\circ} \mathrm{C} / \mathrm{min}$. All of the mixtures doped with catalysts have onset temperatures below $100{ }^{\circ} \mathrm{C}$. Since most of the hydrogen desorbs along the steep portion of the curves it was decided that a more useful way of comparing the dehydrogenation characteristics of materials would be to use the temperature corresponding to the inflection point of each TPD curve. This temperature has been defined as the desorption temperature $\left(\mathrm{T}_{\mathrm{d}}\right)$. The desorption temperatures are given in Table 1. The order of desorption temperatures are $\mathrm{RbH} \leq \mathrm{KH}<\mathrm{CsH}<<$ uncatalyzed. The curves also show that the dehydrogenation capacity of the catalyzed samples are slightly less than 4.2 weight percent whereas that for the un-catalyzed sample is 4.5 weight percent. This is based on the premise that hydrogen release occurs only during the steep portion of the curves. After hydrogen release is complete, there is a pronounced change in the slope of the line. At this point there is a gradual decrease in the baseline but 
this is not due to further hydrogen release. The differences in dehydrogenation capacity between the catalyzed and un-catalyzed samples can be attributed to the weight penalty due to the presence of the catalysts.

\subsection{Pressure Composition Isotherm (PCI) Analysis and van't Hoff Plot}

Desorption pressure composition isotherm measurements were carried out on the mixtures in order to determine the plateau pressures at different temperatures in the $200-230{ }^{\circ} \mathrm{C}$ range. When a desorption PCT isotherm was made at one temperature, the process was to re-hydrogenate the sample (absorption) and then do a second desorption at a different temperature. This demonstrated that the sample was fully reversible with the catalysts added. The role of the catalysts was to make the process occur faster. The plateau pressures were used to construct van't Hoff plots and determine the enthalpy values for the desorption reactions. PCI curves at $210{ }^{\circ} \mathrm{C}$ are presented in Fig. 6 and plateau pressures at $210{ }^{\circ} \mathrm{C}$ are given in Table 1. It can be seen that the plateau pressures of the mixtures are in the order: $\mathrm{RbH} \geq \mathrm{KH}>$ $\mathrm{CsH}>$ Un-catalyzed. Fig. 7 shows the van't Hoff plots for the desorption process involved in the mixtures. The various enthalpy values obtained for the different mixtures are given in Table 1 . The trend in enthalpies is $\mathrm{RbH} \leq \mathrm{KH}<\mathrm{CsH}<$ Un-catalyzed. This trend is similar to those seen in the desorption temperatures in Table 1. As expected, the un-catalyzed mixture displays a much high desorption enthalpy than the catalyzed mixtures due to its high desorption temperature and its lower plateau pressure. The desorption enthalpy for the $\mathrm{CsH}$ doped mixture is slightly higher than the others and thus fits into the expected trend. 


\subsection{Differential Thermal Analysis (DTA) and Kissinger Plot}

Differential Thermal analysis curves were carried out in order to better understand the effects of the catalysts on the dehydrogenation of $\mathrm{LiNH}_{2} / \mathrm{MgH}_{2}$ mixtures. The DTAs were carried out at different heating rates between 4 and $20{ }^{\circ} \mathrm{C} / \mathrm{min}$. Kissinger plots were made from the data obtained. The Kissinger plots were used to determine the activation energies of each mixture. The Kissinger equation was described in our previous paper [31] and by Kissinger [39].

$$
\ln \left(\frac{\beta}{\mathrm{T}_{\max }^{2}}\right)=-\frac{\mathrm{E}_{\mathrm{a}}}{\mathrm{R}}\left(\frac{1}{\mathrm{~T}_{\max }}\right)+\mathrm{F}_{\mathrm{KAS}}(\alpha)
$$

Where $T_{\max }=$ the temperature at maximum reaction rate, $\beta=$ heating rate, $E_{a}=$ the activation energy, $R=$ the gas constant and $F_{K A S}(\alpha)$ is a constant that is a function of the fraction of transformation. Fig. 8 shows the DTA curves for the $\mathrm{CsH}$ doped mixture at different heating rates. It can be seen that the maxima in the DTA curves move to higher values as the heating rates increase. The trends in these curves are similar to those observed for the $\mathrm{KH}$ and $\mathrm{CsH}$ doped mixtures. The Kissinger plots for the various mixtures are shown in Fig. 9. The slopes of these were used to determine activation energies. The activation energies for $\mathrm{KH}$ and $\mathrm{RbH}$ doped mixtures are approximately the same, $87 \mathrm{~kJ} / \mathrm{mol}$ and $86.8 \mathrm{~kJ} / \mathrm{mol}$ respectively. The activation energies follow a similar trend as was seen with enthalpy values: $\mathrm{RbH} \approx \mathrm{KH}>\mathrm{CsH}>$ Un-catalyzed.

\subsection{Kinetics and Modeling}

Fast reaction rates are as important as low desorption temperatures for hydrogen storage systems. Desorption kinetics measurements were carried out for each mixture at $210^{\circ} \mathrm{C}$. All measurements were done at constant pressure thermodynamics forces. As noted earlier, similar 
thermodynamic driving forces were achieved for all of the experiments by using the same ratio of plateau pressure to applied pressure $\left(\mathrm{P}_{\mathrm{m}} / \mathrm{P}_{\mathrm{op}}\right)$ to each sample. A summary of the plateau pressures at $210{ }^{\circ} \mathrm{C}$ is given in Table 1. Fig. 10 contains desorption kinetics plots of the various mixtures. It can be seen that the $\mathrm{RbH}$ doped mixtures has the fastest desorption reaction kinetics when compared with the other doped and un-catalyzed mixtures. The reaction is $90 \%$ completed in about 27 min while the $\mathrm{KH}$ doped mixture took about 62 minutes and the $\mathrm{CsH}$ doped mixture took 76 minutes. The slowest reaction is exhibited by the un-catalyzed mixture that took about 1600 minutes for $90 \%$ completion. Therefore the order of reaction rates is $\mathrm{RbH}>\mathrm{KH}>\mathrm{CsH}>>$ Un-catalyzed.

The kinetics modeling studies were carried out using a shrinking core model. The equations that were fitted to the experimental data are as follows:

$$
\begin{aligned}
& \frac{t}{\tau}=1-\left(1-X_{B}\right)^{1 / 3} \\
& \frac{t}{\tau}=1-3\left(1-X_{B}\right)^{2 / 3}+2\left(1-X_{B}\right)
\end{aligned}
$$

Where $t$ is the time at a specific point in the reaction, $X_{B}$ is the fraction of the metal reacted and $\tau$ is a collection of constants. Statistical methods were used to determine a value for $\tau$ that would minimize the difference between the theoretical and experimental curves. In Equation 3 chemical reaction at the phase boundary controls the reaction rate whereas in Equation 4 diffusion controls the rate. Equations 3 and 4 were fitted to the kinetic data in Fig. 10 for the desorption reactions to determine which kinetic model best describes the reactions in this study. 
Fig. 11 contains three curves for desorption modeling using experimental data for the CsH catalyzed mixture in Fig. 10. One is an experimental data curve; a second curve was calculated from Equation 3 and a third curve was calculated from Equation 4. The data generated from the model with diffusion controlling the overall rate fits the experimental data better than the data generated from the model with chemical reaction controlling the overall reaction rate. The shrinking core model shows that desorption kinetics rates of catalyzed and uncatalyzed mixtures are controlled by a diffusion process at the early stages of the reactions while an unknown process controls the latter part of the reactions. The modeling plots for the KH and $\mathrm{RbH}$ catalyzed mixtures are very similar to that for the $\mathrm{CsH}$ catalyzed mixture. Approximately $60 \%, 74 \%$ and $73 \%$ of $\mathrm{KH}, \mathrm{RbH}$ and $\mathrm{CsH}$ doped mixtures respectively are controlled by diffusion. About $75 \%$ of the un-catalyzed mixture is diffusion controlled.

Since diffusion is the rate-controlling process in these reactions, a plausible explanation can be given for the fact that the $\mathrm{RbH}$ catalyzed mixture desorbs hydrogen faster than the $\mathrm{KH}$ doped mixture. Since $\mathrm{Rb}$ has a larger atomic radius (248 pm) than $\mathrm{K}(227 \mathrm{pm})$, the Rb would cause a greater expansion of the lattice, thereby allowing the diffusing species to move faster through the lattice. However, this does not explain why the $\mathrm{CsH}$ catalyzed mixture desorbs hydrogen slower than the $\mathrm{RbH}$ and $\mathrm{KH}$ doped mixtures. Cs has an atomic radius of $265 \mathrm{pm}$, which is larger than the other two metals. Therefore another factor must be influencing the desorption rates in this mixture. If one examines the XRD patterns in Figure 3 a reason for the anomalous behavior in $\mathrm{CsH}$ is evident. The peaks for all of the mixtures except $\mathrm{CsH}$ show that the imide is produced as the product. In the $\mathrm{CsH}$ catalyzed phase, the imide may not be formed as is evident by the absence of many of the peaks. Since the imide is formed as a product layer through which the hydrogen must diffuse, it is evident that diffusion through the imide is 
controlling the desorption rates in the $\mathrm{RbH}$ and $\mathrm{KH}$ catalyzed mixtures. In the case of the $\mathrm{CsH}$ catalyzed mixture, diffusion through a different layer controls the rate. Apparently the lattice dimensions in this product must be smaller than those in the $\mathrm{RbH}$ and $\mathrm{KH}$ catalyzed mixtures.

Table 1 Summary of desorption parameters for thermodynamics and kinetics results

\begin{tabular}{|c|c|c|c|c|}
\hline Parameter & KH & RbH & CsH & Un-catalyzed \\
\hline Desop. Temp., $\left.\mathbf{T}_{\mathbf{d}}, \mathbf{(}^{\mathbf{0}} \mathbf{C}\right)$ & 146 & 143 & 159 & 237 \\
\hline Desop. $\mathbf{\Delta H}(\mathbf{k J} / \mathbf{m o l})$ & $42.0 \pm 0.5$ & $42.7 \pm 0.2$ & $45.7 \pm 1.1$ & $65.0 \pm 0.3$ \\
\hline Ea (kJ/mol) & $87.0 \pm 2.7$ & $86.8 \pm 0.3$ & $109.1 \pm 2.9$ & $119.0 \pm 6.6$ \\
\hline Pm at 210 ${ }^{\mathbf{C}} \mathbf{C}(\mathbf{a t m})$ & 46.1 & 48.3 & 40.9 & 25.0 \\
\hline $\mathbf{T}_{\mathbf{9 0}} \mathbf{( m i n )}$ & 62 & 27 & 76 & 1600 \\
\hline
\end{tabular}

\section{Conclusions}

The results of this research have shown that the relative effectiveness of the various alkali hydrides in lowering the desorption temperature, lowering the activation energy and increasing hydrogen desorption rates from a $2 \mathrm{LiNH}_{2} / \mathrm{MgH}_{2}$ mixture is in the order: $\mathrm{RbH}>\mathrm{KH}>\mathrm{CsH}$. Modeling studies showed that diffusion is the rate-controlling process in all of the mixtures. In the $\mathrm{RbH}$ and $\mathrm{KH}$ doped mixtures, diffusion in the two-phase plateau region occurs through a $\mathrm{Li}_{2} \mathrm{Mg}(\mathrm{NH})_{2}$ product layer in which part of the $\mathrm{Li}$ is replaced by $\mathrm{Rb}$ or $\mathrm{K}$. The faster kinetics in the $\mathrm{RbH}$ doped mixture is attributed to the fact that $\mathrm{Rb}$ has a larger radius and is thereby able to expand the lattice, thus facilitating the diffusion process. XRD results indicate that the product in the $\mathrm{CsH}$ doped mixture may have different structural characteristics than the other mixtures. Therefore diffusion through this product layer may not be enhanced to the same degree. 


\section{Acknowledgements}

This research was financially supported by the U.S. Department of Energy Award Number DEFC36-06GO86046 and the U.S. Department of Transportation Assistance Number DTOS59-07G-00056.

\section{Figure Captions}

Figure 1 XRD patterns for the catalytic additives

Figure 2 XRD patterns for the as milled mixtures

Figure 3 XRD patterns for the de-hydrided mixtures

Figure 4 XRD patterns for the re-hydrided mixtures

Figure 5 TPD plots for the as-milled $1.9 \mathrm{LiNH}_{2} / 1.1 \mathrm{MgH}_{2}+0.1 \mathrm{MH}(\mathrm{M}=\mathrm{K}, \mathrm{Rb}, \mathrm{Cs})$

Figure $6 \mathrm{PCI}$ desorption curves for $2 \mathrm{LiNH}_{2} / \mathrm{MgH}_{2}$ mixtures at $210{ }^{\circ} \mathrm{C}$

Figure 7 Van't Hoff plots for the $2 \mathrm{LiNH}_{2} / \mathrm{MgH}_{2}$ mixtures

Figure 8 DTA curves for $1.9 \mathrm{LiNH}_{2} / 1.1 \mathrm{MgH}_{2}+0.1 \mathrm{CsH}$

Figure 9 Kissinger plots for the catalyzed and un-catalyzed mixtures

Figure 10 Desorption kinetics for the catalyzed and un-catalyzed mixtures

Figure 11 Modeling plots for the $1.9 \mathrm{LiNH}_{2} / 1.1 \mathrm{MgH}_{2}+0.1 \mathrm{CsH}$ mixture

\section{Table Caption}

Table 1 Summary of desorption parameters for thermodynamics and kinetics results 


\section{References}

1. Schlapbach L; Zuttel A. Hydrogen-storage Materials for Mobile Applications. Nature 2001;414:353-8.

2. Sakintuna B, Lamari-Darkrim F, Hirscher M. Metal hydride materials for solid hydrogen storage: A review. Int J Hydrogen Energy 2007;32:1121-40.

3. Durbin DJ; Malardier-Jugroot C. Review of Hydrogen Storage Techniques for on Board Vehicle Applications. Int J Hydrogen Energy 2013;38:14595-17.

4. Jain I, Jain P, Jain A. Novel hydrogen storage materials: A review of lightweight complex hydrides. J Alloys Compd 2010;503:303-9.

5. Bogdanović B.; Schwickardi M. Ti-doped Alkali Metal Aluminium Hydrides as Potential Novel Reversible Hydrogen Storage Materials. J Alloys Compd 1997;253-254, 1-9.

6. Zaluska A, Zaluski L, Strom-Olsen JO. Sodium alanates for reversible hydrogen storage. J Alloys Compd 2000;298:299-8.

7. Yang H, Ojo A, Ogaro P, Goudy AJ. Hydriding and dehydriding kinetics of sodium alanate at constant pressure thermodynamics driving force. J Phys Chem C 2009;113: $14512-7$.

8. Fang Z, Kang X, Wang P. Improved hydrogen storage properties of $\mathrm{LiBH}_{4}$ by mechanical milling with carbon additives. Int J Hydrogen Energy 2010;35:8247-2.

9. Ibikunle A, Goudy A, Yang H. Effects of Ti-based additives on the hydrogen storage properties of a $\mathrm{LiBH}_{4} / \mathrm{CaH}_{2}$ destabilized system. J Alloys Compd 2009:475:110-5.

10. Sabitu S and Goudy A. Dehydrogenation kinetics and modeling studies of 2 $\mathrm{LiBH}_{4}+\mathrm{MgH}_{2}$ enhanced by $\mathrm{NbF}_{5}$ catalyst. J Phys Chem C 2012;116:13545-0. 
11. Cerny R, Severa G, Ravnsbak D, Filinchuk Y, Anna V, Hagemann H, Haase D, Jensen C, Jensen T. $\mathrm{NaSc}\left(\mathrm{BH}_{4}\right)_{4}$ : a novel scandium-based borohydride. J Phys Chem C 2010;114:1357-4.

12. Pinkerton F. Decomposition kinetics of lithium amide for hydrogen storage materials. J Alloys Compd 2005;400:76-2.

13. Meisner G, Pinkerton F, Meyer M, Balogh M, Kundrat M. Study of the lithiumnitrogen-hydrogen system. J Alloys Compd 2005;404:24-6.

14. Chen P, Xiong Z, Luo J, Lin J, Tan KL, Interaction of hydrogen with metal nitrides and imides. Nature 2002;420:302-4.

15. Luo W. ( $\left.\mathrm{LiNH}_{2}-\mathrm{MgH}_{2}\right)$ : a viable hydrogen storage system. J Alloys Compd 2004;381:284-7.

16. Shahi RR, Yadav TP, Shaz MA, Srivastva ON. Studies on Dehydrogenation Characteristic of $\mathrm{Mg}\left(\mathrm{NH}_{2}\right)_{2} / \mathrm{LiH}$ Mixture Admixed with Vanadium and Vanadium Based Catalysts $\left(\mathrm{V}, \mathrm{V}_{2} \mathrm{O}_{5}\right.$ and $\left.\mathrm{VCl}_{3}\right)$. Int J Hydrogen Energy 2010;35:238-6.

17. Ma LP, Dai HB, Liang Y, Kang XD, Fang ZZ, Wang PJ, Wang P, Cheng HM. Catalytically Enhanced Hydrogen Storage Properties of $\mathrm{Mg}\left(\mathrm{NH}_{2}\right)_{2}+2 \mathrm{LiH}$ Material by Graphite-Supported Ru Nanoparticles. J Phys Chem C 2008;112:18280-5.

18. Hu JJ, Liu YF, Wu GT, Xiong ZT, Chua YS, Chen P. Improvement of Hydrogen Storage Properties of the Li-Mg-N-H System by Addition of $\mathrm{LiBH}_{4}$. Chem. Mater. 2008;20:43982.

19. Hu JJ, Pohl A, Wang SM, Rothe J, Fichtner M. Additive Effects of $\mathrm{LiBH}_{4}$ and $\mathrm{ZrCoH}_{3}$ on the Hydrogen Sorption of the Li-Mg-N-H Hydrogen Storage System. J Phys Chem C 2012;116:20246-3. 
20. Chen Y, Wang P, Liu C, Cheng HM. Improved Hydrogen Storage Performance of LiMg-N-H Materials by Optimizing Composition and Adding Single-walled Carbon Nanotubes. Int J Hydrogen Energy 2007;32:1262-8.

21. Liang C, Liu Y, Wei Z, Jiang Y, Wu F, Gao M, Pan H. Enhanced dehydrogenation/hydrogenation kinetics of the $\mathrm{Mg}\left(\mathrm{NH}_{2}\right)_{2}-2 \mathrm{LiH}$ system with $\mathrm{NaOH}$ additive. Int J Hydrogen Energy 2011;36:2137-44.

22. Li B, Liu Y, Li C, Gao M, Pan H. In situ formation of lithium fast-ion conductors and improved hydrogen desorption properties of the $\mathrm{LiNH}_{2}-\mathrm{MgH}_{2}$ system with the addition of lithium halides. J Mater Chem A 2014;2:3155-62.

23. Cao H, Wu G, Zhang Y, Xiong Z, Qiu J, Chen P. Effective thermodynamic alteration to $\operatorname{Mg}\left(\mathrm{NH}_{2}\right)_{2}$-LiH system: achieving near ambient-temperature hydrogen storage. J Mater Chem A 2014;2:15816-22.

24. Nayebossadri S. Kinetic rate-limiting steps in dehydrogenation of Li-N-H and Li-Mg-NH systems - Effects of elemental Si and Al. Int J Hydrogen Energy 2011;36:8335-43.

25. Liu Y, Hu J, Xiong Z, Wu G. Improvement of the hydrogen-storage performances of LiMg-N-H system. J Mater Res 2007;22:1339-45.

26. Li C, Liu Y, Gu Y, Gao M, Pan H. Improved hydrogen storage thermodynamics and kinetics for as RbF-doped $\mathrm{Mg}\left(\mathrm{NH}_{2}\right)_{2}$-2LiH system. Chem. Asian J. 2013;8:2136-43.

27. Wang JH, Liu T, Wu GT, Li W, Liu YF, Araujo CM, Scheicher RH, Blomqvist A, Ahuja R, Xiong ZT, Yang P, Gao MX, Pan HG, Chen P. Potassium-Modified Mg( $\left.\mathrm{NH}_{2}\right)_{2} / 2 \mathrm{LiH}$ System for Hydrogen Storage. Angew Chem Int Ed 2009;48:5828-2. 
28. Durojaiye T, Goudy A. Desorption kinetics of lithium amide/magnesium hydrided systems at constant pressure thermodynamics forces. Int Journal of Hydrogen Energy 2012;37: 3298-3304.

29. Luo W, Stavila V, Klebanoff LE. New Insights into the Mechanism of Activation and Hydrogen Absorption of (2 $\mathrm{LiNH}_{2}-\mathrm{MgH}_{2}$ ). Int J Hydrogen Energy 2012;37:6646-2.

30. Li C, Liu Y, Pang Y, Gu Y, Gao M, Pan H. Compositional effects on the hydrogen storage properties of $\mathrm{Mg}\left(\mathrm{NH}_{2}\right)_{2}-2 \mathrm{LiH}-\mathrm{xKH}$ and the activity of $\mathrm{KH}$ during dehydrogenation reactions. Dalton Trans., 2014;43:2369-77.

31. Durojaiye T, Hayes J, Goudy A. Rubidium Hydride: An Exceptional Dehydrogenation Catalyst for the Lithium Amide/Magnesium Hydride System. J Phys Chem C 2013;117:6554-60.

32. Jacobs H, Birkenbeul J, Kochelkorn J. Darstellung und Eigenschaften der Amidomagnesate des Kaliums und Rubidiums $\mathrm{K}_{2}\left[\mathrm{Mg}\left(\mathrm{NH}_{2}\right)_{4}\right]^{-}$und $\mathrm{Rb}_{2}\left[\mathrm{Mg}\left(\mathrm{NH}_{2}\right)_{4}\right]^{-}$ Verbindungen mit Isolierten $\left[\mathrm{Mg}\left(\mathrm{NH}_{2}\right)_{4}\right]^{2-}$-Tetraedern. (Preparation and Properties of Amidomagnesate of potassium and rubidium $\mathrm{K}_{2}\left[\mathrm{Mg}\left(\mathrm{NH}_{2}\right)_{4}\right]^{-}$und $\mathrm{Rb}_{2}\left[\mathrm{Mg}\left(\mathrm{NH}_{2}\right)_{4}\right]^{-}$ Connections with insulated $\left[\mathrm{Mg}\left(\mathrm{NH}_{2}\right)_{4}\right]^{2-}$-Tetrahedra). J Less Common Met 1984;97:20514.

33. Jacobs H, Birkenbeul J, Schmitz D. Struktur verwandtschaft des dicaesiumamidomagnesats, $\mathrm{Cs}_{2}\left[\mathrm{Mg}\left(\mathrm{NH}_{2}\right)_{4}\right]$, zum $\beta-\mathrm{K}_{2} \mathrm{SO}_{4}$-Typ (Structural relationship of dicaesiumamidomagnesats, $\mathrm{Cs}_{2}\left[\mathrm{Mg}\left(\mathrm{NH}_{2}\right)_{4}\right]$, to $\beta-\mathrm{K}_{2} \mathrm{SO}_{4}$-Type). J Less Comm Met 1982;85:79-6.

34. Elansari L, Antoine L, Janot R, Gachon J, Kuntz J, Guerard D. Preparation of alkali metal hydrides by mechanical alloying. J Alloys Compd 2001;329:L5-8. 
35. Saidi S, Goudy A. Dehydrogenation kinetics and modeling studies of $2 \mathrm{LiBH}_{4}+\mathrm{MgH}_{2}$ enhanced by $\mathrm{NbF}_{5}$ catalyst J Phys Chem C 2012;116:13545-0.

36. Smith G, Goudy AJ. Thermodynamics, kinetics, and modeling studies of the $\mathrm{LaNi}_{5-\mathrm{x}} \mathrm{Co}_{\mathrm{x}}$ Hydride System J. Alloys Compds. 2001;316:93-8.

37. Ibikunle AA, Goudy AJ. Kinetics and modeling study of a $\mathrm{Mg}\left(\mathrm{BH}_{4}\right)_{2} / \mathrm{Ca}\left(\mathrm{BH}_{4}\right)_{2}$ destabilized system. Int Journal of Hydrogen Energy 2012;37:12420-4.

38. Hu J, Fichtner M. Formation and Stability of Ternary Imides in the Li-Mg-N-H Hydrogen Storage System. Chem. Mater. 2009;21:3485-90.

39. Kissinger HE. Reaction kinetics in differential thermal analysis. Anal Chem 1957;29:1702-6. 


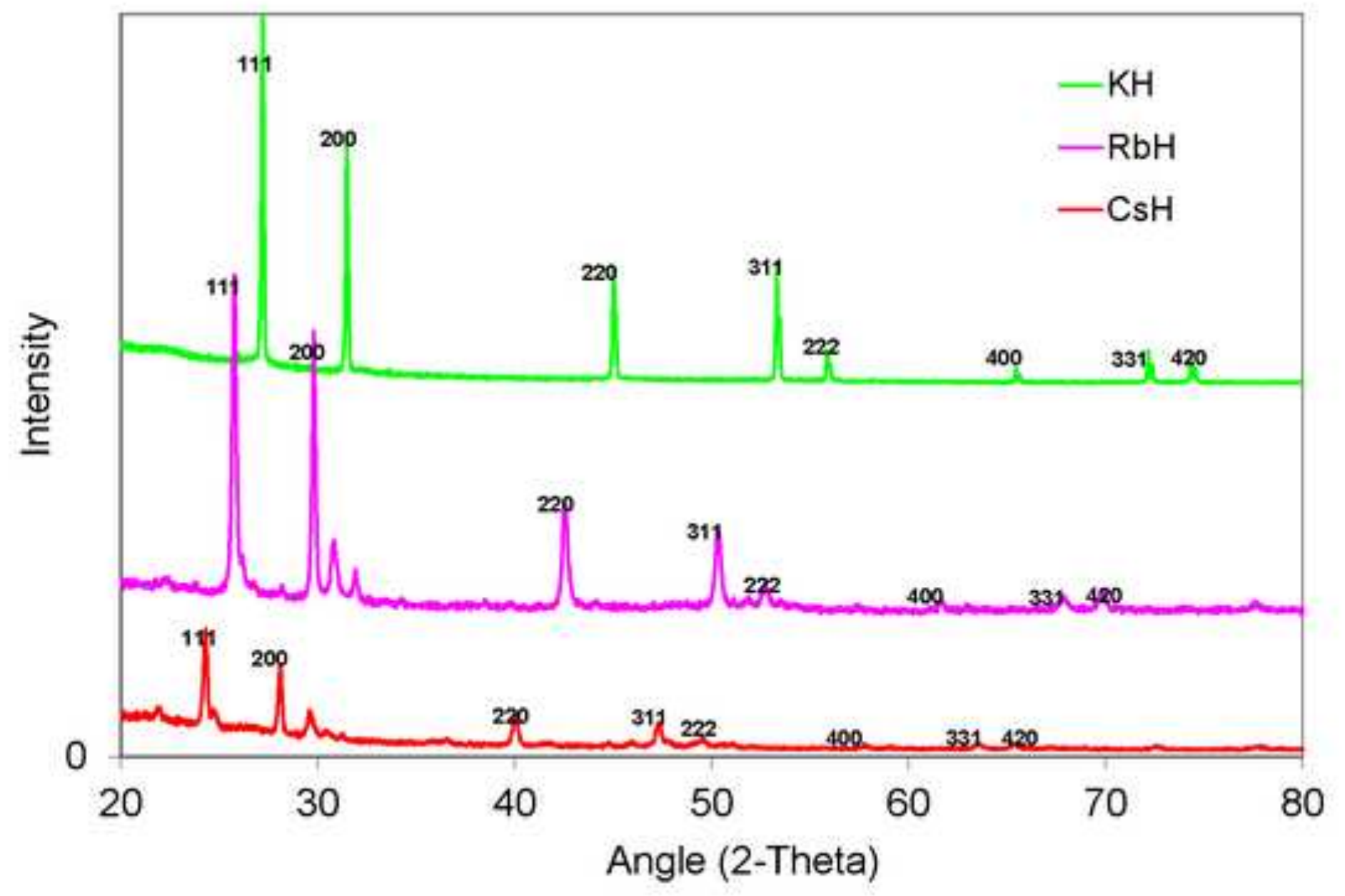




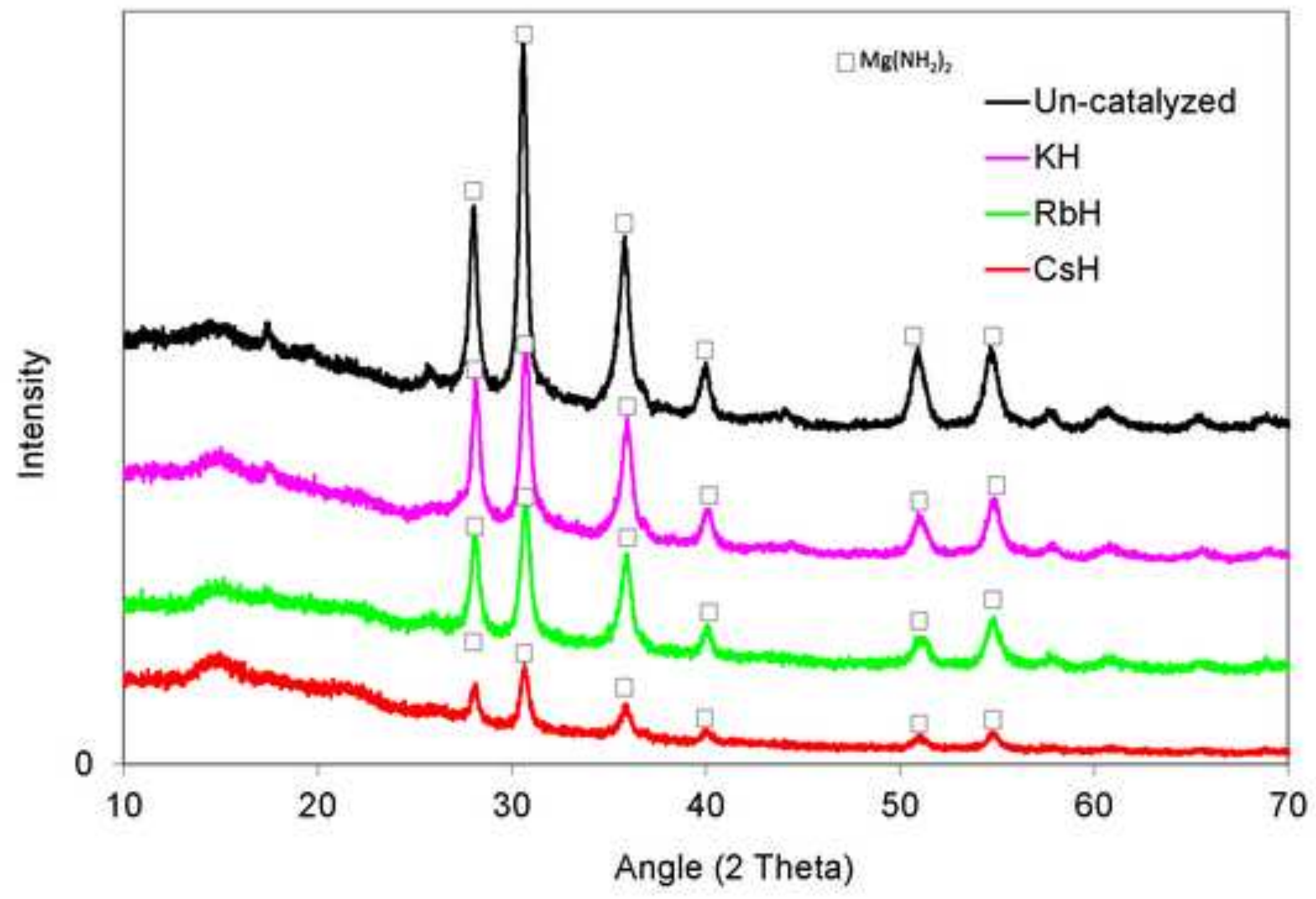




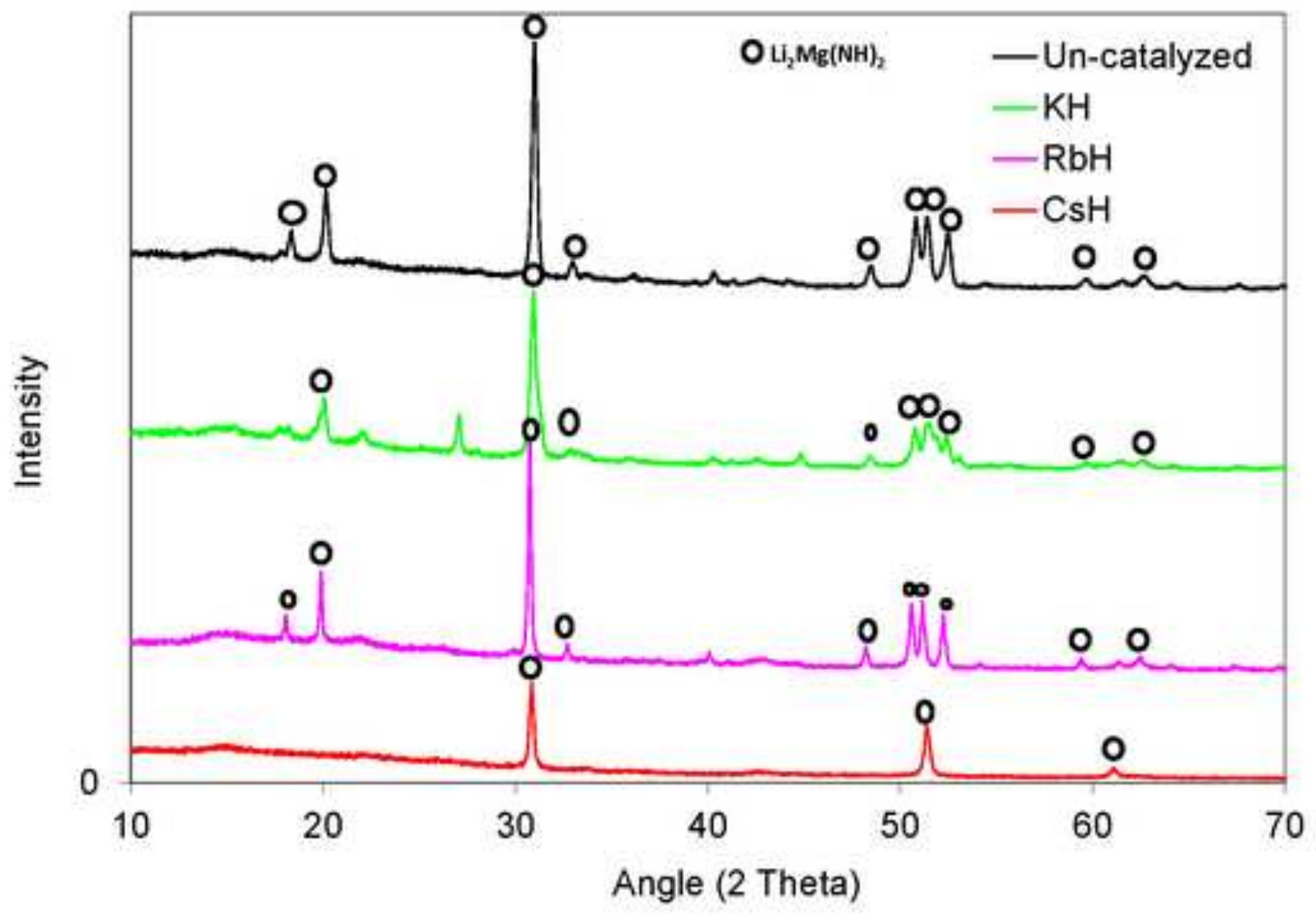




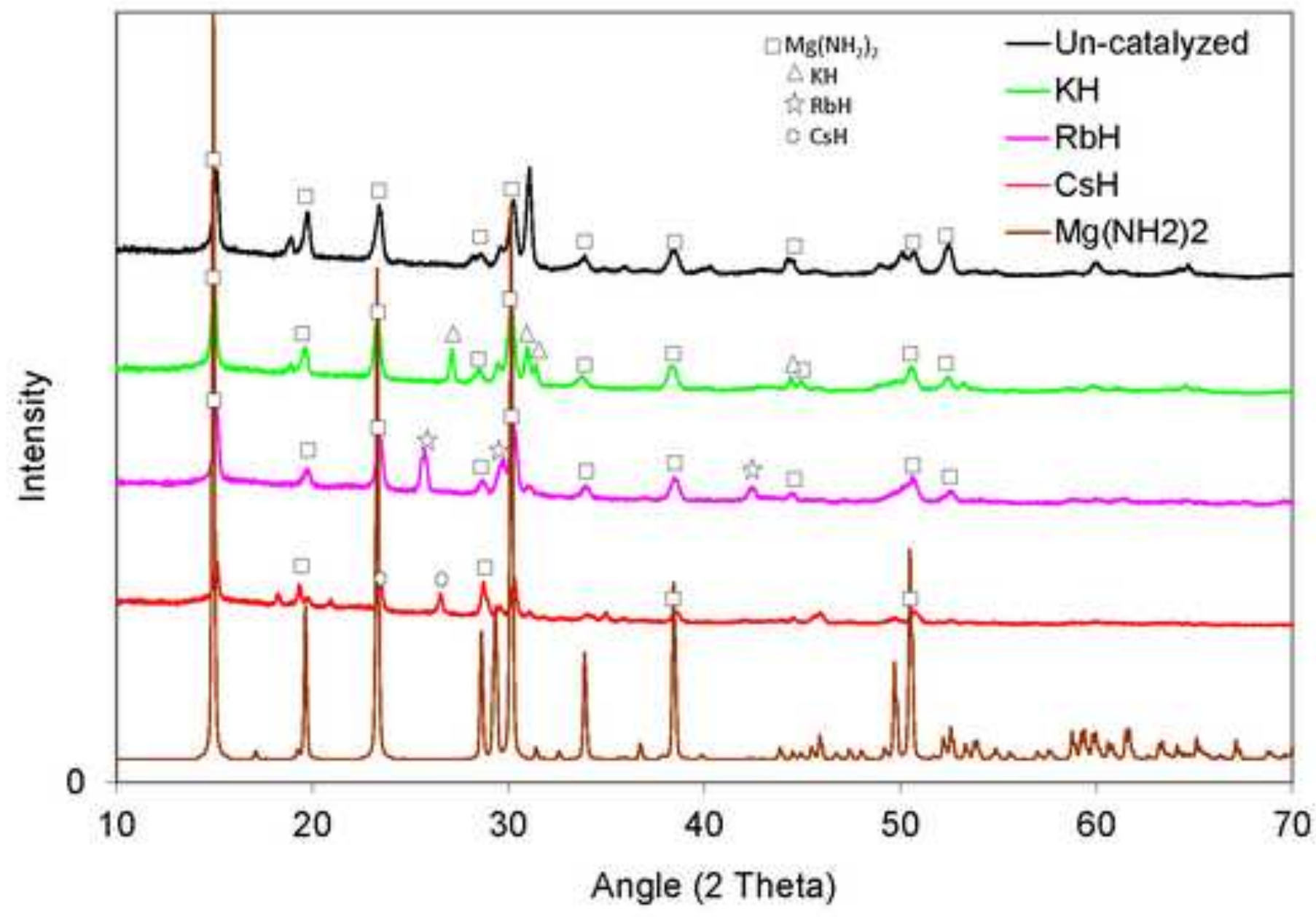




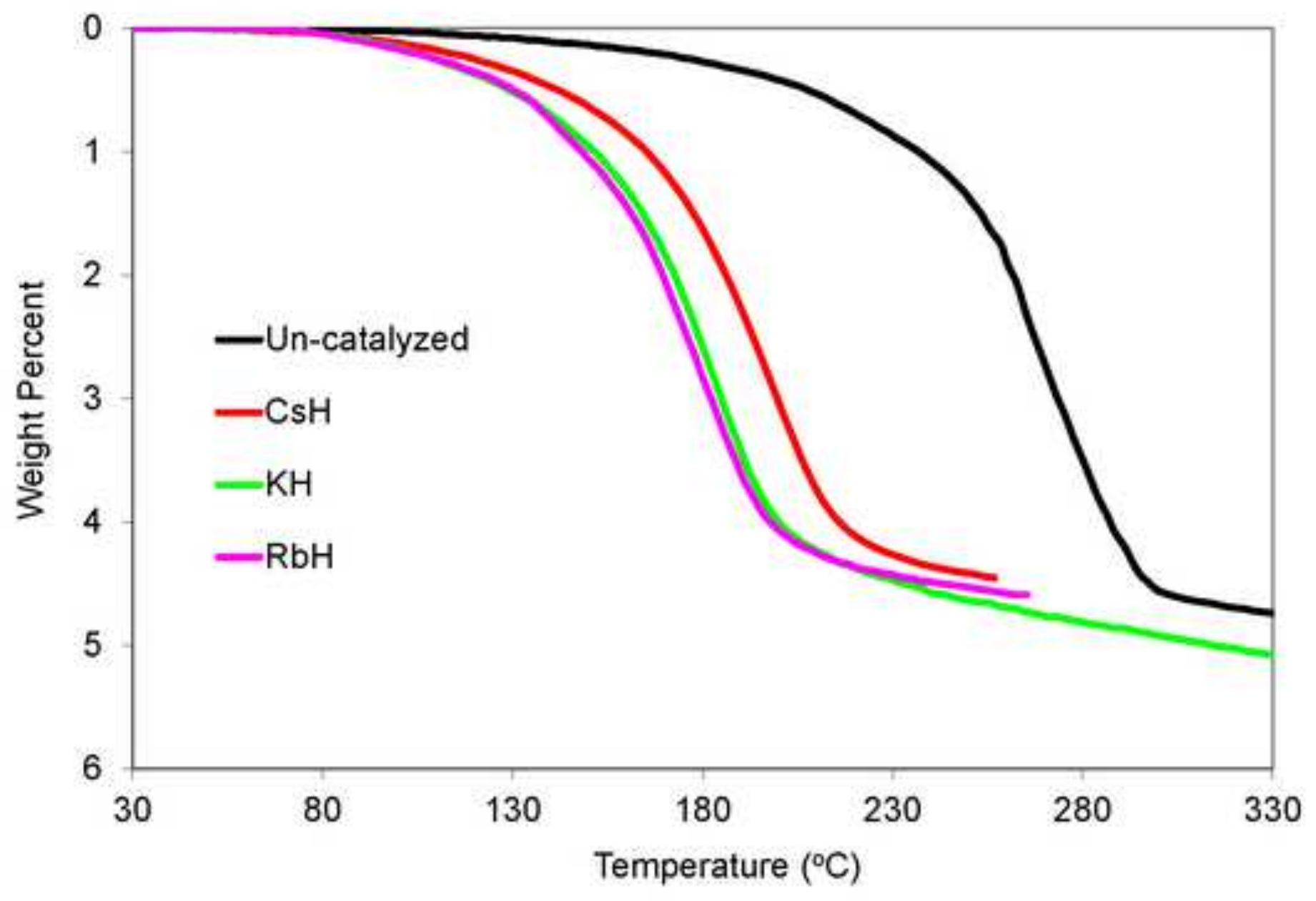




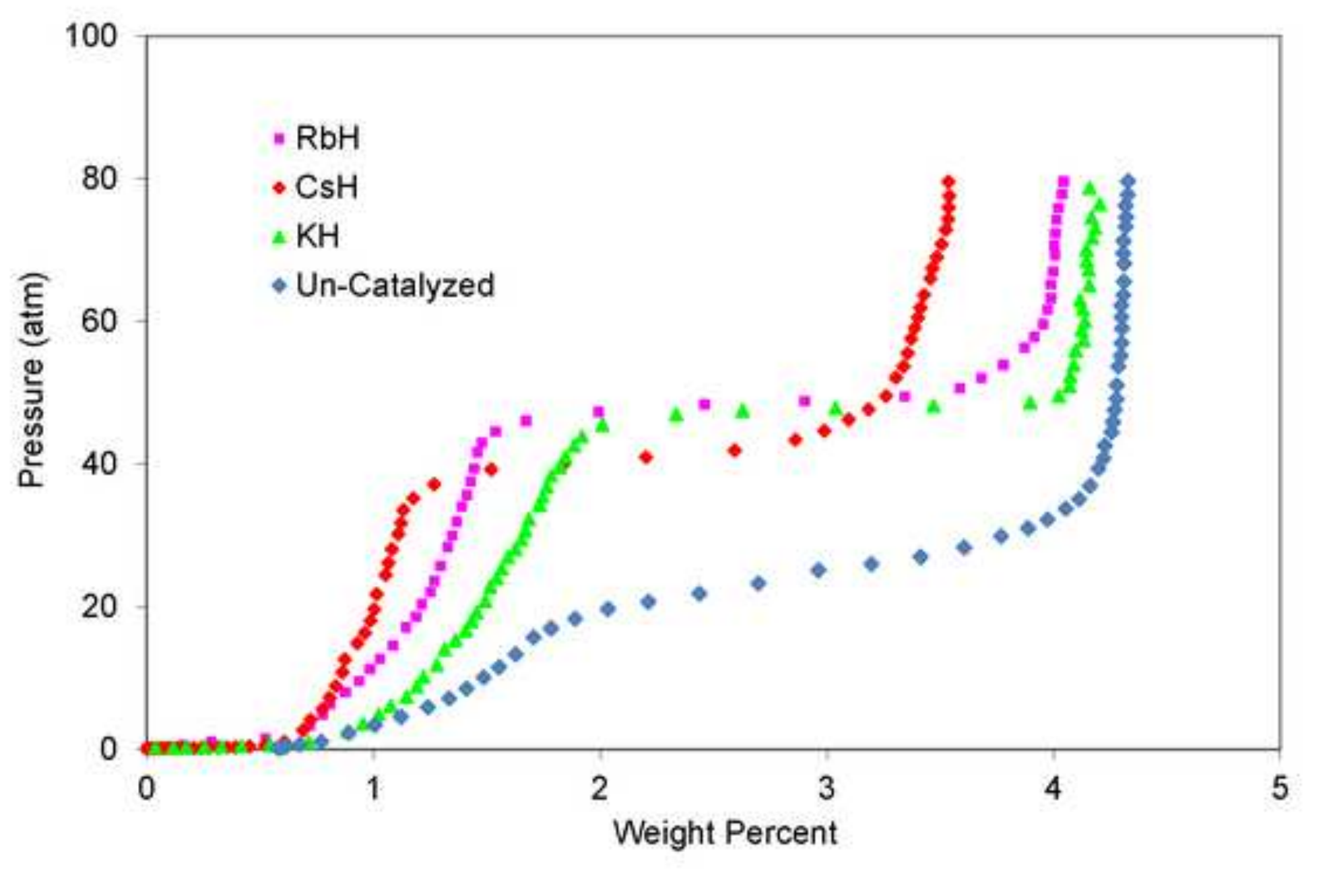

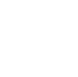

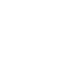




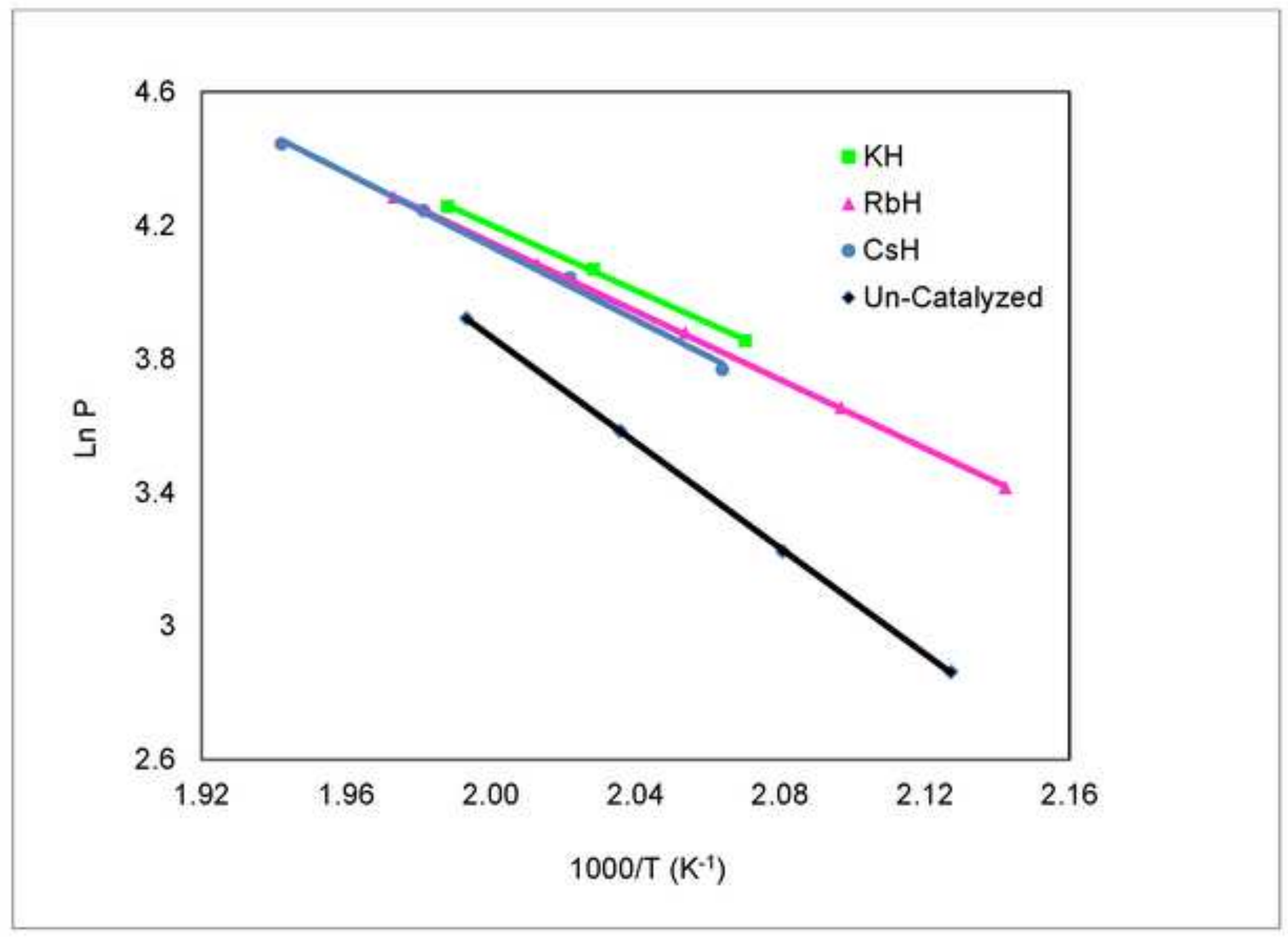




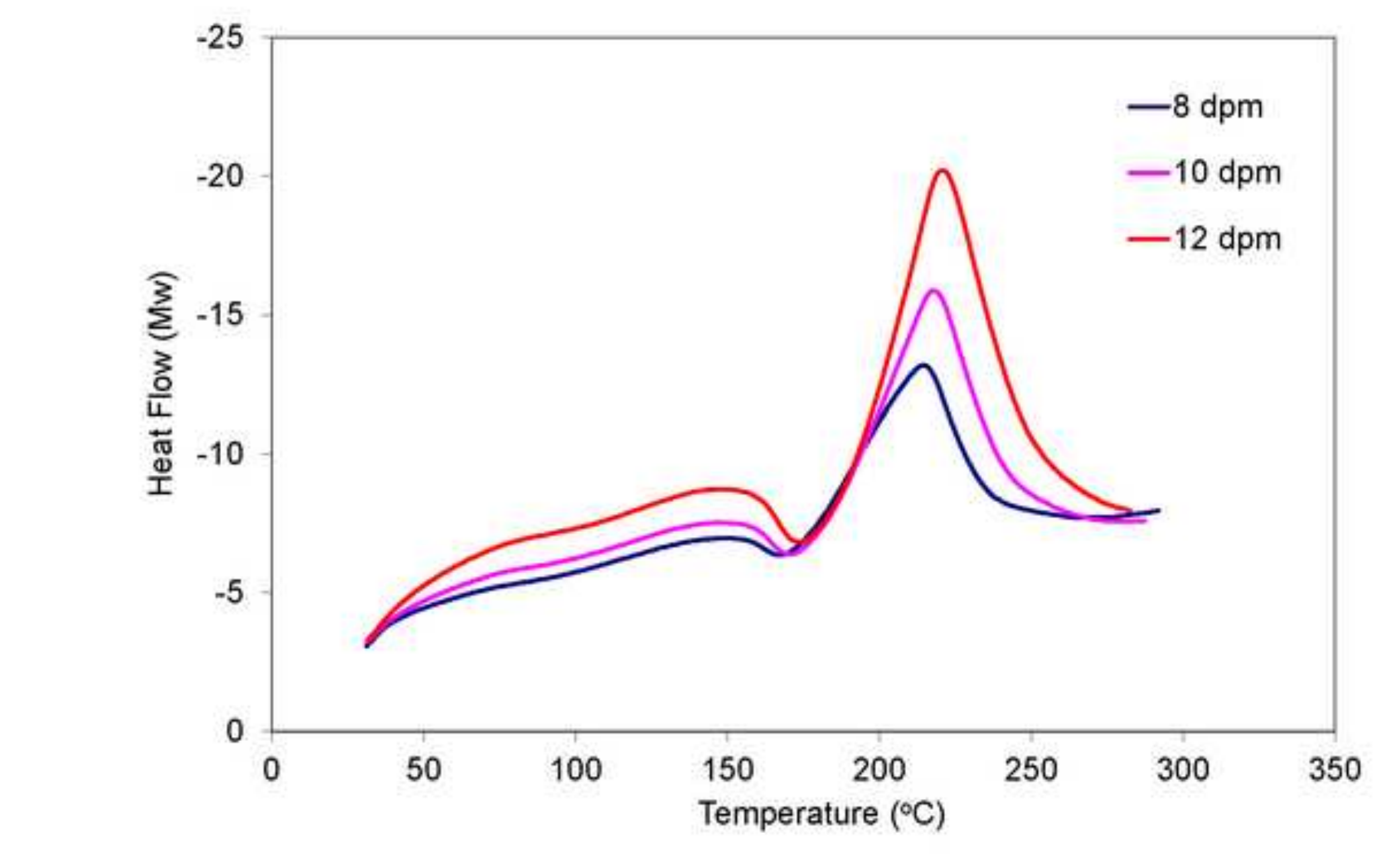




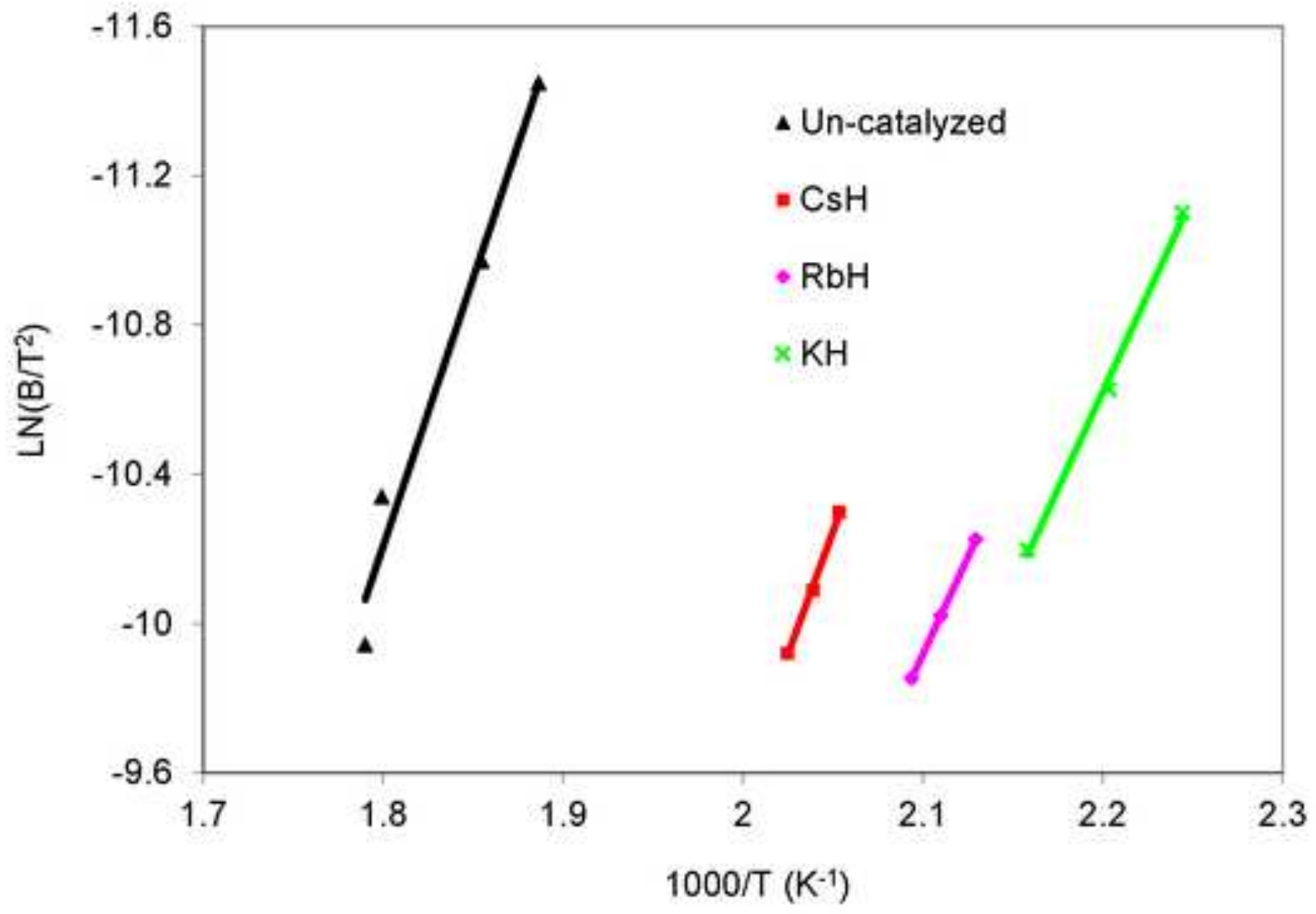




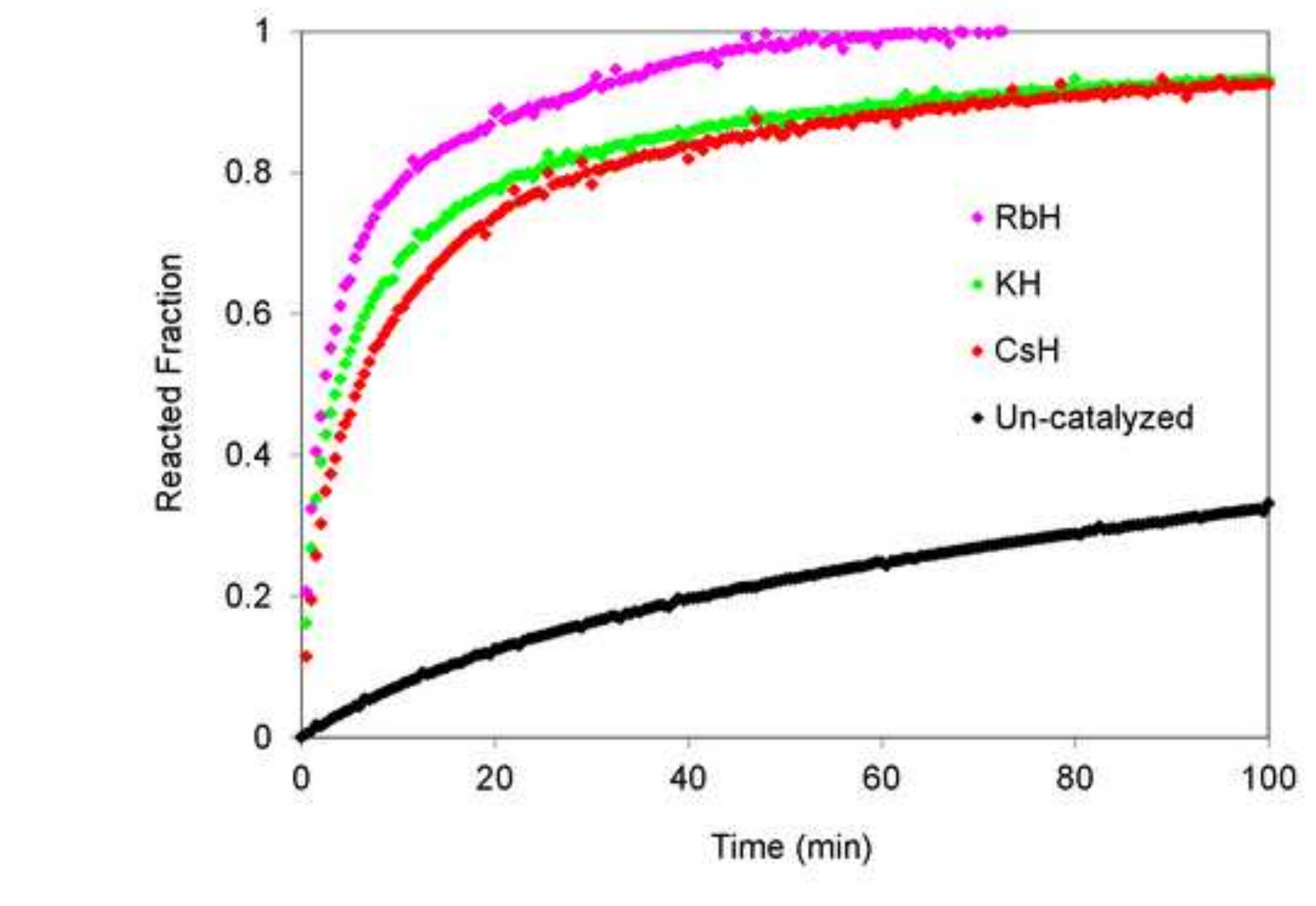




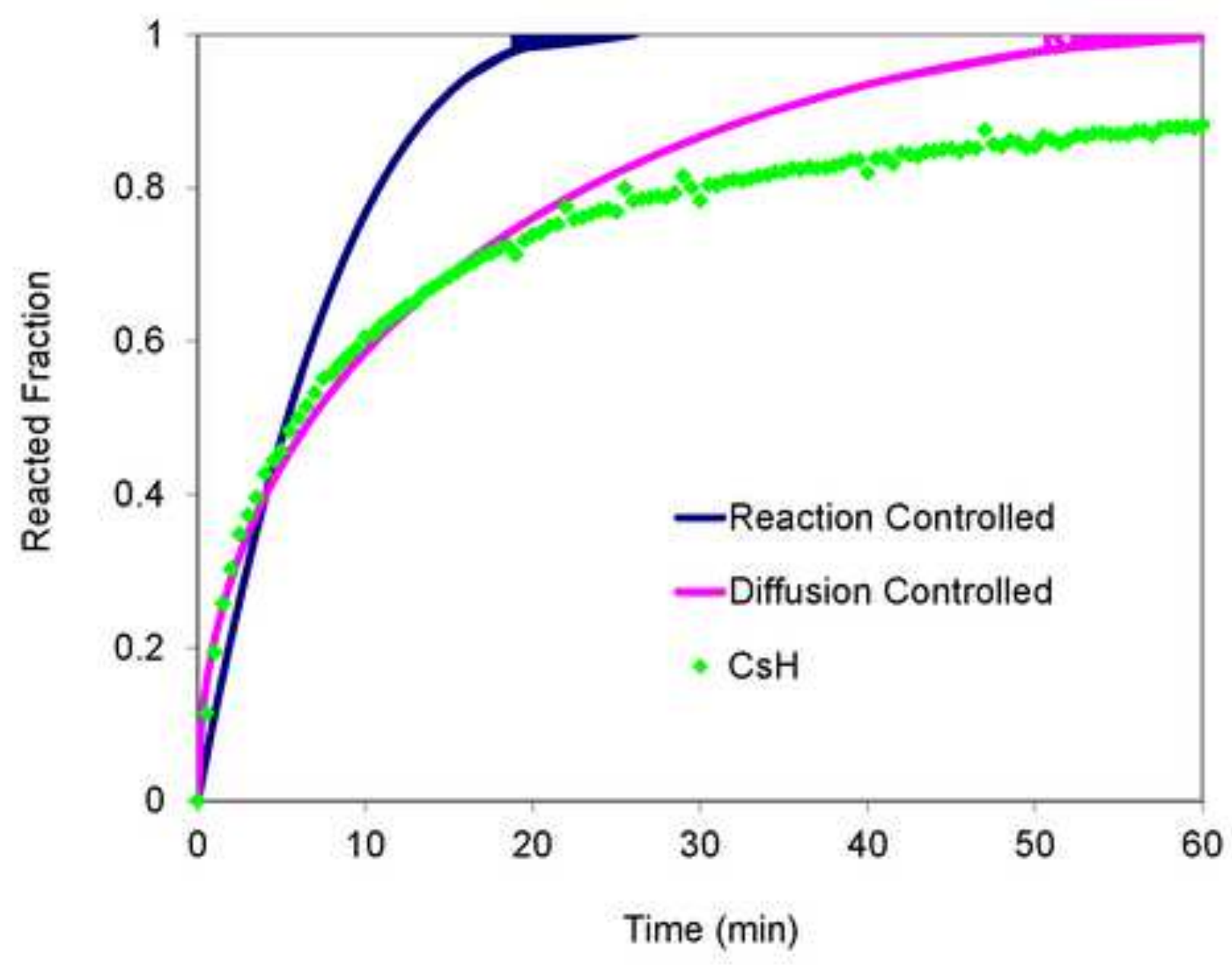




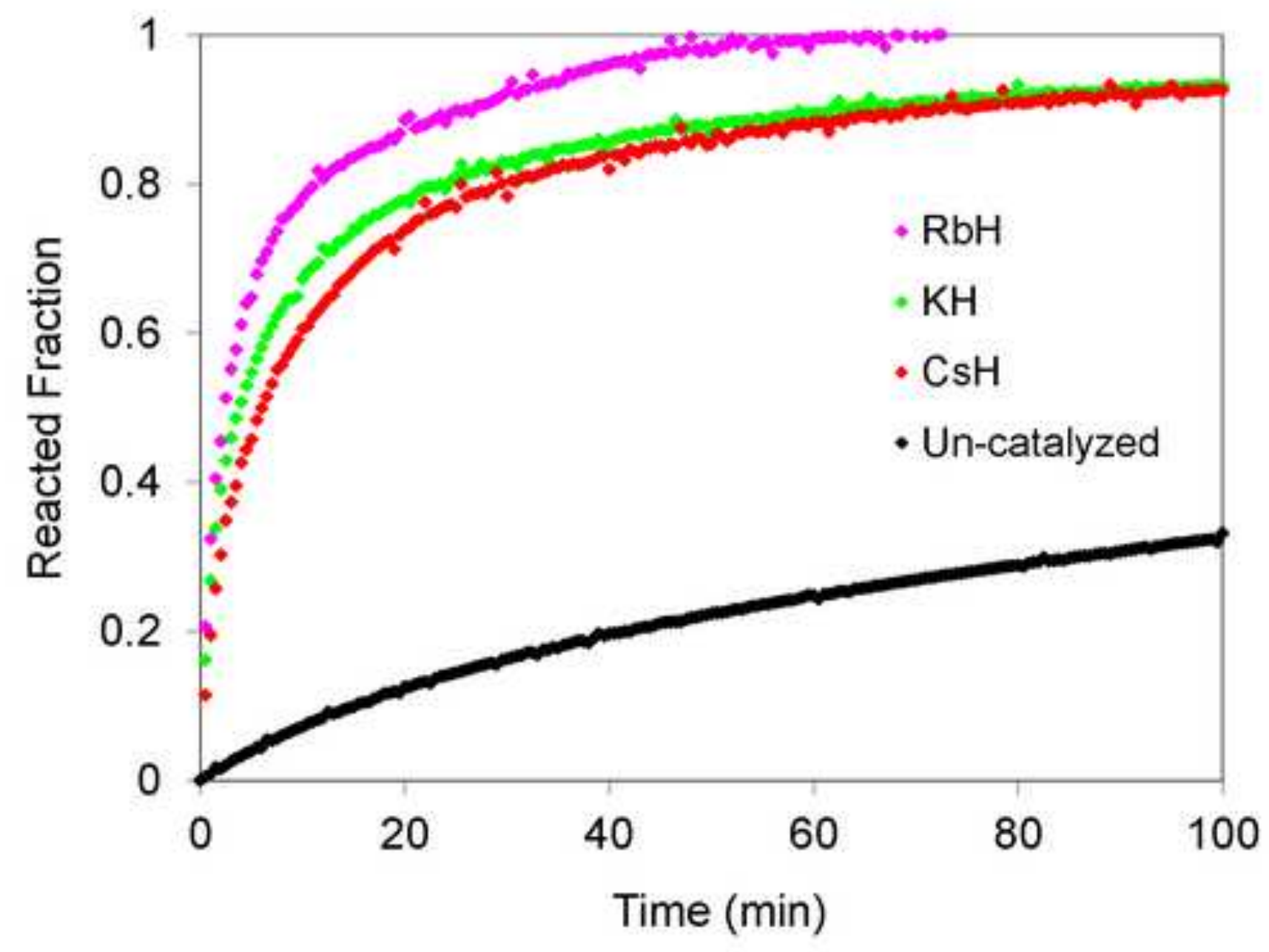




\begin{tabular}{|c|c|c|c|c|}
\hline Parameter & KH & RbH & CsH & Un-catalyzed \\
\hline Desop. Temp., $\left.\mathbf{T}_{\mathbf{d}}, \mathbf{(}^{\mathbf{0}} \mathbf{C}\right)$ & 146 & 143 & 159 & 237 \\
\hline Desop. $\mathbf{\Delta H}(\mathbf{k J} / \mathbf{m o l})$ & $42.0 \pm 0.5$ & $42.7 \pm 0.2$ & $45.7 \pm 1.1$ & $65.0 \pm 0.3$ \\
\hline Ea (kJ/mol) & $87.0 \pm 2.7$ & $86.8 \pm 0.3$ & $109.1 \pm 2.9$ & $119.0 \pm 6.6$ \\
\hline Pm at 210 ${ }^{\mathbf{0}} \mathbf{C}(\mathbf{a t m})$ & 46.1 & 48.3 & 40.9 & 25.0 \\
\hline $\mathbf{T}_{\mathbf{9 0}}(\mathbf{m i n})$ & 62 & 27 & 76 & 1600 \\
\hline
\end{tabular}


List of 3 suggested reviewers

Ragaiy Zidan

Savannah River National Laboratory

999-2W

Aiken, SC 29803

Phone: 803-725-1726

E-mail: ragaiy.zidan@snrl.doe.gov

Isaac Jacob

Ben Jurion University

Department of Nuclear Engineering

Beer Sheva, 84105 Israel

Phone: 972-8-646-1316

Email: $\underline{\text { izi@bgu.ac.il }}$

Chris Wolverton

Northwestern University

Dept. of Materials Sci. and Eng.

2220 Campus Drive

Evanston, IL 60208

Phone: 847-467-0593

Email: c-wolverton@northwestern.edu 